\author{
Cadernos de \\ ESTUDOS LNGGḯlsTICOS - (55.1), Campinas, Jan./Jun. 2013
}

\title{
ENTRELAÇANDO FRAMES: A CONSTRUÇÃO DO SENTIDO METAFÓRICO NA LINGUAGEM EM USO
}

\author{
SOLANGE VEREZA ${ }^{1}$
}

\begin{abstract}
RESUMO
Este artigo tem como foco a reflexão sobre a linguagem metafórica em uso. A abordagem defendida busca articular os planos de sentido "e" (estável) e "e" (episódico/emergente) para compreender a construção metafórica no discurso. Entre os aspectos constituintes de ambos os planos, os frames (online e off-line) se mostram como conceitos centrais na produção de sentidos figurados na linguagem em uso.
\end{abstract}

Palavras- chave: metáfora; discurso; frames.

\begin{abstract}
This article has as its focus the metaphoricity found in language in use. The approach to be proposed aims at articulating the planes of meaning "e" (stable) and "e""(episodic) in order to understand metaphorical constructions. Among the aspects characteristic of both planes, frames (online and offline) were found to be central in figurative meaning production.
\end{abstract}

Keywords: metaphor; discourse; frames.

\section{A METÁFORA NO DISCURSO}

As pesquisas na área da metáfora foram significativamente impulsionadas pela introdução, mais sistemática², da Teoria da Metáfora Conceptual (TMC), proposta por Lakoff e Johnson (1980 [2002]). A TMC, além de oferecer uma conceituação revolucionária da metáfora, deslocando o seu lócus da linguagem para o pensamento (VEREZA, 2010), apontou caminhos instigantes e promissores para os estudos na área. Novas perguntas de pesquisas e metodologias foram formuladas para esses estudos que, em seu conjunto, formaram um campo de investigação bastante profícuo (já conhecido como metaforologia (STEEN, 1994)), que teve repercussões nas diversas áreas dos estudos da linguagem

1. UFF, Niterói (RJ), Brasil. svereza@uol.com.br

2. Parece haver um consenso de que os principais pressupostos que sustentam o conceito de "metáfora conceptual" já haviam sido introduzidos por teóricos anteriores a Lakoff e Johnson, sendo que o próprio Lakoff (1993) explicita a influência do trabalho de Reddy (1979) no desenvolvimento de sua proposta. Acreditamos, no entanto, que a sistematização e a formalização do conceito em uma teoria (mesmo que essa ainda não tivesse sido cunhada como Teoria da Metáfora Conceptual), foram efetivamente efetuadas somente a partir da obra seminal Metaphors we Live by (1980). 
VEREZA - Entrelaçando frames: A construção...

(particularmente, é claro, na linguística cognitiva (GEERAERTS, 1996)) e da literatura (STEEN, 1994; LAKOFF E TURNER, 1989), como também em outras ciências humanas.

Mais recentemente, no entanto, já se pode observar um conjunto significativo e diversificado de críticas dirigidas à TMC. Entre essas $^{3}$, as problematizações quanto a sua rigidez teórica e opacidade analítica vêm redirecionando novas pesquisas ao encontro dos estudos do discurso. Ou seja, houve uma série de inquietações, por parte de vários pesquisadores (por exemplo, CAMERON, 1999, 2008; DEIGNAN, 2005; SEMINO, 2008; ZANOTTO et al, 2008), acerca do caráter predominantemente dedutivo das pesquisas envolvendo a TMC (a busca de evidências para corroborar metáforas conceptuais propostas a priori) e do fato da TMC não contemplar os aspectos dinâmicos e contextuais da metaforicidade, característicos da metáfora em uso.

Segundo Cameron e Deignan (2006),

A virada cognitiva deslocou, deliberadamente, a atenção dada à língua. Embora exemplos linguísticos sejam citados em todos os estudos relevantes da área, sua importância reside não nas expressões propriamente ditas, mas na evidência do elo cognitivo que elas representam. Com o foco em sistemas conceptuais compartilhados, a abordagem cognitiva para o uso da metáfora ignora, inevitavelmente, o poder da experiência linguística de um indivíduo. ${ }^{4}$ (CAMERON e DEIGNAN, 2006, p. 672)

Nesse movimento em direção à compreensão da metáfora na "experiência linguística", unidades analíticas foram desenvolvidas para o estudo sistemático da metáfora em uso. A primeira delas, a metáfora sistemática, proposta por Cameron (2008) e Cameron e Maslen (2010), refere-se a todo um conjunto de metáforas linguísticas, encontradas em textos autênticos, que podem ser semanticamente relacionadas. A metáfora sistemática, como a metáfora conceptual, é implícita, mas evocada por meio de expressões interligadas; ou seja, é de caráter predominantemente cognitivo. No entanto, ao contrário da metáfora conceptual, a metáfora sistemática tem sua dimensão cognitiva atrelada a textos específicos, não fazendo parte, necessariamente, de um sistema abstrato de produção de significados que abranja toda uma língua e cultura, como é o caso da metáfora conceptual. Em outras palavras, a metáfora sistemática é "episódica" e se enquadra em uma perspectiva de cognição "online".

Outra unidade é o metaforema (CAMERON e DEIGNAN, 2006), uma metáfora nova introduzida em um dado contexto, a qual, a partir das características próprias deste contexto (visto pelas autoras como um "sistema complexo") encontra plena ressonância semântico-discursiva para emergir. O metaforema, dessa forma, pode ser tratado como uma metáfora emergente, candidata à convencionalização,

3. Para uma discussão mais detalhada dessas críticas, ver SCHRÖDER, 2011.

4. No original: The cognitive turn thus deliberately shifted the attention away from language. While linguistic examples are cited throughout the central work in the field, their importance is as evidence for cognitive links rather than in themselves. With this focus on shared conceptual systems, a cognitive explanation of metaphor use inevitably ignores the possible explanatory power of an individual's previous experience with language. Minha tradução. 
podendo ultrapassar os limites do contexto em que surge. Tanto a metáfora sistemática quanto o metaforema, representam conceitos independentes de uma possível relação cognitiva com metáforas conceptuais subjacentes. Quando isso acontece - no caso, por exemplo, de uma metáfora sistemática poder ser analiticamente associada a uma metáfora conceptual- a associação não é vista como algo necessário, nem mesmo relevante para os resultados da análise proposta.

O nicho metafórico seria ainda outra unidade de análise da metáfora em uso. Segundo Vereza (2007), esta unidade pode ser definida como

um grupo de expressões metafóricas, inter-relacionadas, que podem ser vistas como desdobramentos cognitivos e discursivos de uma proposição metafórica superordenada normalmente presente (ou inferida) no próprio cotexto (VEREZA, 2007, p. 496).

Ao contrário da metáfora sistemática, o nicho metafórico não remete a uma única metáfora cognitiva, mas a toda uma rede metafórica que vai sendo tecida em uma unidade semântico-discursiva construída textualmente.

Além do foco da unidade não se limitar a expressões metafóricas específicas encontradas em determinados textos, orais ou escritos, o nicho metafórico é abordado teórica e analiticamente como um segmento de linguagem em uso que evidencia a estreita relação entre a linguagem e a cognição, sendo essa última tratada a partir tanto de seus aspectos episódicos (online), quanto daqueles mais estáveis (off-line).

Nas diversas propostas de análise de nichos metafóricos (VEREZA 2006, 2010 e 2012), busca-se justamente a articulação entre esses dois níveis de cognição, sempre a partir do compromisso de não se desprezar os inquestionáveis ganhos teóricos da Teoria da Metáfora Conceptual.

\section{A METÁFORA CONCEPTUAL NA LINGUAGEM EM USO}

Na perspectiva da TMC, expressões metafóricas encontradas na linguagem, tanto as mais convencionalizadas quanto as mais criativas, seriam instanciações de metáforas conceptuais subjacentes. Entretanto, de acordo com pesquisas de base psicolinguística (GIBBS, 1984; GIBBS et al, 1997, 1999, entre outras), não há evidências de que essa instanciação na linguagem se traduza, no processamento, em uma ativação mental da metáfora conceptual subjacente às expressões metafóricas. Muitas das críticas feitas hoje à Teoria da Metáfora Conceptual dizem respeito justamente ao fato de que esses estudos parecem refutar a hipótese de que metáforas conceptuais seriam acionadas na compreensão de expressões idiomáticas licenciadas por tais metáforas. Uma vez que não se pode comprovar esse acionamento, ficaria difícil também comprovar a existência de metáforas conceptuais subjacentes.

No entanto, há que se dicotomizar, teoricamente, as noções de instanciação e de ativação (ou acionamento). A primeira se enquadra dentro de uma perspectiva de "motivação", em nível de sistema. Instanciações - uma noção também muito cara à Linguística Sistêmica Funcional, de Michael Halliday (HALLIDAY e 
VEREZA - Entrelaçando frames: A construção...

MATTHIESSEN, 2004) - são materializações verbais de expressões que foram licenciadas por metáforas conceptuais, que não precisam necessariamente ser "ativadas" no processamento online. Ou seja, estamos falando de uma perspectiva de motivação linguística, e não psicolinguística. Dessa forma, o conceito de metáfora conceptual não se enfraquece epistemologicamente pelo fato de que, em pesquisas experimentais, ele não pode ser comprovado pela possibilidade (ou não) de sua realidade psicológica. Por estar inserida no nível do sistema, a metáfora conceptual deve ser primordialmente abordada como uma estrutura cognitiva $^{5}$ abstrata de geração de sentidos a serem instanciados na linguagem verbal, aqui incluindo tanto o léxico quanto a gramática, e visual (FORCEVILLE C. J. e URIOS-APARISI, 2009). A Gramática das Construções (GOLDBERG, 2006) é um bom exemplo de como a metáfora pode fundamentar até mesmo construções gramaticais normalmente não contempladas pelos estudos gramaticais convencionais (ver, por exemplo, MIRANDA, 2009 e BRONZATO, 2012). As metáforas conceptuais, por sua vez, emergiriam da experiência, tanto corpórea (LAKOFF e JOHNSON, 1999) quanto cultural (KÖVECSES, 2005) do homem no mundo, a partir de projeções entre domínios dessa experiência.

Dentro dessa perspectiva, estudar a metáfora conceptual na linguagem em uso não é tarefa fácil, justamente pelo fato de esta encontrar o seu lócus no sistema. Nesse sentido, a linguística de corpus (LC), que pode ser concebida como um tipo de estudo da linguagem em uso, seria mais adequada à investigação da metáfora conceptual (DEIGNAN, 2005) por permitir a análise de instanciações autênticas de possíveis licenciamentos de metáforas conceptuais. No entanto, a LC, apesar da autenticidade e da relativa representatividade de seu material linguístico, não oferece subsídios para se investigar a metaforicidade online. $\mathrm{Ou}$ seja, mesmo retratando a linguagem em uso, a LC contempla apenas o retrato (por mais amplo e nítido que seja) e não a dinâmica da construção de sentidos característica da enunciação em que a metáfora em uso se insere. Sendo assim, não podemos afirmar que haja abordagens analíticas que tratem, sistematicamente, da metáfora conceptual em sua relação com a metaforicidade que emerge a partir da dinâmica da linguagem em uso.

Algumas análises de nichos metafóricos, como o encontrado no TEXTO I, parecem mostrar claramente os mapeamentos desenvolvidos a partir de uma metáfora conceptual de base (no caso DISCUSSÃO /NEGOCIAÇÃO É GUERRA). As instanciações linguísticas desses mapeamentos (armas do domínio fonte "guerra" vis-a-vis armas do domínio alvo "discussão") seriam as evidências da metáfora subjacente em questão.

5. É preciso ressaltar que a noção de cognição em que o conceito de metáfora conceptual se insere é de natureza experiencial e cultural (LAKOFF e JOHNSON, 1980 [2002]), afastando-se, assim, da cognição de caráter inatista, pressuposta pela gramática gerativa. 


\section{TEXTO I}

A Guerra entre o Ocidente e o Irã sobre o programa nuclear iraniano é ao mesmo tempo sutil e dura. Envolve armas de todos os tipos: diplomacia, sanções, ameaças, blefes, verdades, mentiras e muita espionagem.

Fonte: O GLOBO, 25/05/2012. p. 6.

A metaforicidade construída nos vários nichos estudados (ibid.) é, de um modo geral, nitidamente dependente de instâncias cognitivas transcendentes ao texto, mas, em alguns casos, ao contrário do que acontece no TEXTO I, não se pode afirmar, categoricamente, que essas instâncias representem metáforas conceptuais. No nicho desenvolvido no TEXTO II, abaixo, a metaforicidade estabelecida entre a língua e uma duna de areia, apesar de muito bem mapeada discursivamente, garantindo o que Black (1962) chama "lugares comuns associados" (associate commonplaces), não é facilmente traduzível em uma única metáfora conceptual, como no caso do TEXTO I.

\section{TEXTO II}

A língua é mais como dunas de areia do que como estruturas de plano, como um edifício [...].Dunas de areia apresentam regularidades de forma e estrutura aparentes; no entanto, exibem também uma variação considerável entre indivíduos. ${ }^{6}$

Fonte: BYBEE, J. Language, Usage and Cognition. Oxford: OUP. 2010.

Há aqui um claro mapeamento, textualmente desenvolvido, para fins tanto argumentativos quanto epistêmicos, entre a língua e dunas de areia. Mesmo assim, propor uma metáfora conceptual (ou mais de uma) a ser evocada nesta construção não é algo simples. Podemos pensar, obviamente, em esquemas imagéticos (LAKOFF 1987), que, de fato, poderiam ser aplicados em quase toda construção metafórica dessa natureza, mas não, com a mesma segurança analítica, em metáfora conceptuais

Essa falta de clareza, em alguns casos, quanto às possíveis metáforas conceptuais subjacentes à metáfora em uso não implica, no entanto, a rejeição de uma proposta que busque articular os dois planos de cognição (episódico ou estável / online ou off-line), igualmente fundamentais na construção do sentido metafórico na linguagem em uso.

Se, por um lado, a metáfora conceptual nem sempre se mostra nitidamente evocada em grande parte dos nichos estudados - a não ser com um grande esforço, por parte do analista, de extrapolar mapeamentos das candidatas a metáforas

6. No original: Language is more like sand dunes than like a planes structure, such as a building. [...] Sand dunes have apparent regularities of shape and structure; yet, they also exhibit considerable variation among individuals. Minha tradução 
VEREZA - Entrelaçando frames: A construção...

subjacentes - por outro, a noção de frame surge como conceito essencial para o entendimento da produção de sentidos metafóricos na linguagem em uso. Dessa forma, compreender como os frames participam dessa significação figurada representa um passo importante na direção do refinamento de futuras análises de nichos metafóricos.

\section{FRAMES NA METÁFORA EM USO}

A noção de frame abarca uma série de definições, não mutualmente excludentes. Ao contrário, todas parecem remeter, direta ou indiretamente, ao conceito clássico formalizado por Charles Fillmore, que serve como fundamento para o desenvolvimento de sua Semântica de Frames (Frame Semantics). Segundo o autor,

Com o termo "frame" eu tenho em mente um sistema de conceitos relacionados de tal forma que, para entender qualquer um deles, é necessário entender toda a estrutura em que se insere; quando uma coisa nesta estrutura é introduzida em um texto, ou em uma conversa, todas as outras são automaticamente disponibilizadas. Eu pretendo que a palavra "frame", como aqui usada, signifique um termo geral para se referir ao conjunto de conceitos conhecidos na literatura como: "esquema", "script", "cenário", "andaime ideacional", "modelo cognitivo ou "teoria popular". (FILLMORE, 2006, p. 373)

Podemos acrescentar outros conceitos similares ou relacionados, também usados na literatura, como "conhecimento compartilhado", "horizonte de expectativas" e, no caso mais específico da metáfora, e já citados anteriormente, "lugares comuns associados" (BLACK, 1962).

Lakoff (2004), para discorrer sobre o fenômeno de reframing ${ }^{8}$ (que é muito relevante para a questão da metáfora em uso, aqui em foco) propõe que frames sejam definidos como "estruturas mentais que moldam a maneira que vemos o mundo" (LAKOFF, 2004, p. xv). Como se pode observar, essas definições e termos, apesar de algumas diferenças de enfoque, são usados para se referir a algum tipo de estrutura que organiza cognitivamente a experiência (e o conhecimento desta proveniente). Coulson (2001) ressalta um aspecto dos frames que nos interessa particularmente: o fato de eles serem usados para explicar a habilidade humana de fazer inferências em situações complexas a partir de pressupostos compartilhados (COULSON, 2001, p. 20).

7. No original: By the term 'frame' I have in mind any system of concepts related in such a way that to understand any one of them you have to understand the whole structure in which it fits; when one of the things in such a structure is introduced into a text, or into a conversation, all of the others are automatically made available. I intend the word 'frame' as used here to be a general cover term for the set of concepts variously known, in the literature on natural language understanding, as 'schema', 'script', 'scenario', 'ideational scaf-folding', 'cognitive model', or 'folk theory'. Minha tradução.

8. Segundo Lakoff (2004), reframing seria um processo de mudança em frames mais estáveis; uma nova maneira de se conceptualizar um dado fenômeno a partir de estruturas conceptuais, já existentes e pervasivas em uma dada cultura. 
É justamente na natureza dessas inferências, em sua articulação com os frames, que reside a grande questão que envolve a relação entre frames e a linguagem metafórica em uso. Tanto Coulson (2001) quanto Hougaard e Oakley (2008) questionam a propriedade de se usar uma teoria de frames, que seriam instâncias referentes à memória mais de longo prazo, de caráter mais estável e fundadas por representações prototípicas da experiência, para dar conta da "flexibilidade cognitivo-discursava que as pessoas demonstram em seu uso cotidiano da linguagem" (COULSON, 2001, p. 28). Segundo a autora, seria necessário um processo constante de frame shifting (mudança de frames) para viabilizar cognitivamente a produção e a compreensão da metáfora no discurso. Além disso, segundo o mesmo raciocínio, a linguagem em uso não seria apenas um campo empírico de instanciações ou manifestações de blocos estanques de significações. Coulson (ibid.) e Hougaard e Oakley (2008) apresentam uma proposta de frames online, semelhante a dos espaços mentais e da mesclagem (FAUCONNIER (1985) e FAUCONNIER e TURNER (1998), respectivamente.

Nos nossos estudos da linguagem figurada em nichos metafóricos, pudemos verificar o papel fundamental dos frames, nos moldes clássicos descritos por Fillmore e Lakoff, mencionados anteriormente, no estabelecimento da metaforicidade em nível textual. A noção de frames online e a de espaços mentais, mesmo sendo essa última atrelada à existência de um espaço genérico, não parecem dar conta, satisfatoriamente, da centralidade de representações cognitivas compartilhadas (ou seja, frames, no sentido clássico) necessárias para a construção do sentido figurado na linguagem em uso. Já que uma metáfora (linguística ou conceptual) só se enquadra como elemento da significação a partir de projeções, mais ou menos claras, do domínio fonte para o domínio alvo, seria imprescindível termos conhecimento acerca do primeiro domínio para que possamos estabelecer os "lugares comuns associados" e assim "construir o sentido da metáfora."

O conhecimento prévio e compartilhado sobre o domínio fonte, que pode ser visto como sendo formado por um ou mais frames específicos, é, quase sempre, pressuposto na linguagem metafórica em uso. Nesses frames, estariam não só aspectos semânticos do(s) veículo(s), no termos de Richard (1936), mas também socioculturais. A relevância dos frames, nessa perspectiva, pode ser evidenciada no nicho metafórico desenvolvido no TEXTO $3 .^{9}$

\footnotetext{
9. As traduções dos textos III e IV se encontram no ANEXO. A escolha de um texto em língua inglesa, retirado de um jornal americano, justifica-se pelo fato de que a importância dos frames na metaforicidade do nicho em questão torna-se ainda mais evidente, pelo fato de se inserir em uma outra cultura.
} 


\section{TEXTO III}

\section{Rabbit-Hole Economics Paul Krugman}

Reading the transcript of Tuesday's Republican debate on the economy is like falling down a rabbit hole. Suddenly, you find yourself in a fantasy world where nothing looks or behaves the way it does in real life.

And since economic policy has to deal with the world we live in, not the fantasy world of the G.O.P.'s imagination, the prospect that one of these people may well be our next president is terrifying.

In the real world, recent events were a devastating refutation of the free-market orthodoxy that has ruled American politics these past three decades. Above all, the long crusade against financial regulation, the successful effort to unravel the prudential rules established after the Great Depression on the grounds that they were unnecessary, ended up demonstrating that those rules were necessary, after all.

But down the rabbit hole, none of that happened. We didn't find ourselves in a crisis because of runaway private lenders like Countrywide Financial. [...] No, in the universe of the Republican Party we found ourselves in a crisis because Representative Barney Frank forced helpless bankers to lend money to the undeserving poor. [...]

It's a terrible thing when an individual loses his or her grip on reality. But it's much worse when the same thing happens to a whole political party.[...]

October 13, 2011. New York Times - Opinion Page

Fonte: http://www.nytimes.com/2011/10/14/opinion/rabbit-hole-economics.html. Acesso 30/04/2012.

A projeção textualmente construída, para fins argumentativos, entre o discurso do Partido Republicano americano (alvo) e "a toca do coelho" (fonte), vale-se de todos os pressupostos associados ao domínio fonte em questão. O conhecimento de que a "toca do coelho" refere-se à obra Alice no País das Maravilhas, do escritor inglês Lewis Caroll, e de que a toca, na história, é o que leva Alice a penetrar em um mundo de fantasia, de enganos, onde nada é o que parece, mostra-se primordial para a efetivação da metaforicidade pretendida. Na cultura anglo-saxã, a expressão "down the rabbit hole" já é tão marcada culturalmente que parece ter se convencionalizada: a definição, com este sentido metafórico, está, inclusive, disponibilizada na Wikipedia ${ }^{10}$.

Projetar esse sentido na conceptualização avaliativa do discurso de um partido político significa trazer os atributos relevantes do domínio fonte, pertencentes ao frame evocado a partir de "down lhe rabbit hole". É preciso ressaltar, no entanto, que não são todos os elementos constituintes do frame que são mapeados. No desenvolvimento discursivo do ponto de vista, no editorial, construído em grande parte pela linguagem metafórica, apenas os atributos que podem reforçar o argumento participam das projeções. Na definição da Wikipedia, por exemplo, a viagem "down the rabbit hole" pode significar uma aventura rumo ao desconhecido

10. "down the rabbit hole": a metaphor for adventure into the (potentially weird) unknown, from its use in Alice's Adventures in Wonderland. Wikipedia. Acesso 20/04/2012. 
Cadernos de ESTUDOS LINGǘlSTICOS (55.1) - Jan./Jun. 2013

que, dependendo do alvo, poderá adquirir um aspecto positivo, referente aos sonhos e à fantasia (como quando dizemos, por exemplo: "aquela viagem foi um sonho"), mesmo que haja um certo estranhamento. Ou seja, o mapeamento é, de alguma forma, seletivo, e é somente dentro do nicho, como um todo, que a sua natureza semântico-pragmática será estabelecida. No caso do nicho em questão, a crítica ao Partido Republicano (muitas vezes antecipada pelo conhecimento sobre o gênero (editorial), a posição política do jornal (considerada predominantemente democrata) e o próprio jornalista/escritor conduzem as projeções para que essas contribuam para a construção discursiva e a força persuasiva do argumento central: o discurso do Partido Republicano é falacioso por se distanciar do mundo real e se apoiar em quimeras.

O nicho em questão também evoca um frame (em seu sentido de teoria popular) ainda mais amplo, relacionado ao valor atribuído ao "mundo real", em oposição ao "mundo da fantasia". Esse último, por se distanciar da "verdade", deve ser visto pelo homem adulto, com desconfiança e até mesmo desdém. Um outro editorial (TEXTO IV), do mesmo jornal, utiliza-se de outros veículos, do domínio fonte "Terra da Fantasia", para desenvolver seu nicho.

\section{TEXTO IV}

\section{Hard Road Ahead Bob Herbert}

Walt Disney would have been proud of John McCain's presentation on Thursday of what the world might look like at the end of a first McCain term as president.

Listening to the speech was like walking through the gates of Fantasyland, which Disney always said was the happiest kingdom of them all. The war in Iraq will have been won. Taxes will be lower and the U.S. economy will be swell. Senator McCain never bothered to mention how we were to reach this wondrous state, and he bristled when a reporter suggested he was offering a "magic carpet ride."

Elisabeth Bumiller of The Times had the best line when she wrote in Friday's paper that "there were no real checkable facts in Mr. McCain's divination." On the same day that the senator unveiled his candy-coated vision, a former governor of West Virginia, Bob Wise, came by my office to talk about a much more prosaic matter - the terrible job that the nation is doing in getting its high school kids ready for the real world.

[...] The role of the federal government in improving secondary education should be one of the major issues in the presidential campaign, but it's not. The U.S. has stopped dealing honestly with difficult and complex problems. Politicians spin fantasies of a wondrous, cost-free future. [...]

May 17, 2008 New York Times - Opinion Page

Fonte: http://www.nytimes.com/2008/05/17/opinion/17herbert.htmlHardRoadsAhead. Acesso 30/04/2012.

Ambos editoriais têm como alvo de crítica (e, ao mesmo tempo, alvo dos mapeamentos ou projeções), o Partido Republicano ou, metonimicamente, políticos deste partido. Para fortalecer a argumentação, frames (off-line) são evocados na produção de frames episódicos. Não compartilhamos da visão de que haja necessariamente uma mudança de frame (frame shifting), como crê Coulson (2001), 
mas sim um entrelace de frames estáveis e episódicos, que surgem como resultado dos mapeamentos, sendo, portanto texto-específicos. Vale também observar que haveria a possibilidade de se proporem metáforas conceptuais subjacentes, no nível estável e/ou off-line de sentidos, que, de certa forma, licenciariam os nichos analisados. Uma delas, bastante genérica, seria CONHECER É VER, supondo-se que o alvo de conhecer seria a verdade. O mundo da fantasia, presente no mundo de Alice, na Terra do Disney, em histórias das mil e uma noites (tapetes mágicos), não está ao alcance dos olhos e, portanto, pertence ao mundo das sombras que impediriam a visão nítida do real. Uma outra possibilidade, relacionada à anterior, seria REALIDADE É UM OBJETO TANGÍVEL, objeto este que pode (e deve) ser segurado com firmeza; afinal, temos que ter um "grip" firme sobre ele. Dessa forma, em níveis ainda mais superiores, podemos propor, em alguns casos, estruturas de sentido estáveis, como as metáforas conceptuais que, juntamente com os frames, participam da figuratividade textual.

A articulação entre frames online e off-line, no entanto, não é, necessariamente, equilibrada em todos os nichos analisados. Em alguns deles, como no caso do TEXTO V, o frame episódico tem um papel muito mais relevante do que o off-line na construção da metaforicidade.

\section{TEXTO V}

\section{Um Diálogo com a Música}

[...]Recentemente, comecei a investir em uma questão ainda pouco explorada: poderia a música fornecer modelos teóricos, expressivos, ou até mesmo metáforas que contribuíssem para a renovação da historiografia?

Como a minha principal área de estudos é a Teoria da História - aquele campo no qual o objeto de estudo é a própria obra dos historiadores de todas as épocas, inclusive a nossa -, cheguei à conclusão de que poderia usar a música para entender a complexidade teórica dos diversos historiadores que se tornaram autores de obras importantes. Ao lado de conceitos já clássicos, como os de "paradigma", "escola histórica" e "campo histórico", surgiu-me a possibilidade de trabalhar com uma nova noção, inspirada na teoria musical. Esta nova noção - o "acorde teórico" - tem a função de contrabalançar a simplificação na qual nos envolvemos quando tentamos compreender o trabalho de um historiador usando apenas as noções de "paradigma historiográfico" e "escola histórica".

Um acorde, na teoria e na prática musical, pode ser entendido como um conjunto de notas musicais que soam juntas, e assim produzem uma sonoridade compósita. Por meio de uma pauta de cinco linhas, pode-se representar um acorde musical. Mas o acorde é um fenômeno sonoro, independente da representação que lhe atribuamos em uma folha de papel. O acorde teórico, em minha reflexão, se transformou em um recurso para expressar a interação dos diversos aspectos que compõem a identidade de um historiador, considerando que nenhum deles cabe inteiramente dentro de paradigmas como o positivismo, o historicismo ou o materialismo histórico. O paradigma é apenas um dos acordes teóricos do autor. [...]

Fonte: BARROS, J. D. Revista de História, n. 71, agosto de 2011, p. 67.

Aqui, o autor não pressupõe o acionamento de frames do domínio fonte (acorde musical), pois antecipa uma não familiaridade do leitor com esse domínio. 
Para estabelecer, portanto, a metaforicidade, neste caso de caráter epistêmico, o autor descreve os elementos relevantes desse frame, para a criação de seu objeto de discurso, para só aí criar o entrelace (frame episódico). Ou seja, o que podemos pensar como um "frame-fonte" não é concebido como sendo suficientemente compartilhado, para além da comunidade discursiva pertencente ao mundo da música. Os aspectos que são acionados nessa descrição (do acorde musical) seriam aqueles mais relevantes que participariam do mapeamento proposto, do frame episódico "acorde teórico".

Um exemplo radicalmente oposto seria o do TEXTO VI (não caracterizado como um nicho metafórico, propriamente), em que o frame implícito ao termo "Pré-Sal" é completamente pressuposto:

\title{
TEXTO VI
}

\begin{abstract}
Abram Alas
Um estudo do Fórum Econômico Mundial, publicado no ano passado, situou o Brasil em 52o lugar num ranking de competitividade turística internacional. A colocação até que não seria má, se o Brasil não tivesse emplacado um primeiro lugar num dos quesitos mais importantes da avaliação: riquezas naturais. Os 51 postos que separam uma posição da outra são a medida exata do potencial que temos a desenvolver. O turismo internacional é um segundo Pré-sal.[...]. Já somos os turistas mais cobiçados do mundo. Está mais do que na horas de nos tornarmos um destino cobiçado também.
\end{abstract}

Fonte: FREIRE, R. Revista Gol, n. 122, 2012, p. 150.

O autor não oferece, explicitamente, as bases para o mapeamento entre o domínio fonte "Pré-Sal" e o domínio alvo "turismo brasileiro. Ou seja, o frame off-line é dado como compartilhado. O frame episódico, que estabelece a projeção entre fonte e alvo, também não é desenvolvido textualmente. A argumentação do texto em si pode ser vista como um frame online de caráter argumentativo, em que o objeto de discurso "turismo brasileiro" está sendo construído como algo que tem um grande potencial ainda longe de ser plenamente explorado. Esse frame, como um todo, pelas teias de sua argumentação, juntamente com o uso da palavra "potencial", pode oferecer os elementos cognitivos necessários para o acionamento dos elementos do frame mais estável "Pré-Sal". Mas, como no caso de muitas metáforas novas, a dependência de inferências sem o conforto cognitivo de frames subjacentes implica sempre um "ato discursivo de risco".

\section{ENTRELACES DOS PLANOS ESTÁVEIS E EPISÓDICOS}

Uma proposta analítica, brevemente ilustrada com os exemplos apresentados nas páginas anteriores, que visa à compreensão da relação entre planos de sentido de naturezas ao mesmo tempo opostas e complementares, certamente não pode dar conta dos múltiplos aspectos envolvidos nesta articulação. O que parece ficar 
VEREZA - Entrelaçando frames: A construção...

evidente, a partir desses exemplos, no entanto, é que estudar a metáfora em uso não significa a exclusão da reflexão acerca do papel dos planos mais estáveis de sentido, como as metáforas conceptuais, os frames, os esquemas imagéticos, os M.C.I.s (modelos cognitivos idealizados, LAKOFF, 1987), entre outros. Não nos parece razoável limitar essa linha de investigação às instâncias do plano episódico, sob à luz exclusiva dos processos enunciativos ou discursivos, ou mesmo daqueles referentes à cognição online (como o processamento). A alternativa aqui delineada, muito brevemente, devido ao escopo deste artigo, parte de uma proposta de entrelace entre os diversos elementos dos dois planos, para que a construção do sentido metafórico na linguagem em uso possa ser mais bem compreendida. A figura abaixo procura ilustrar, graficamente, esse entrelace.

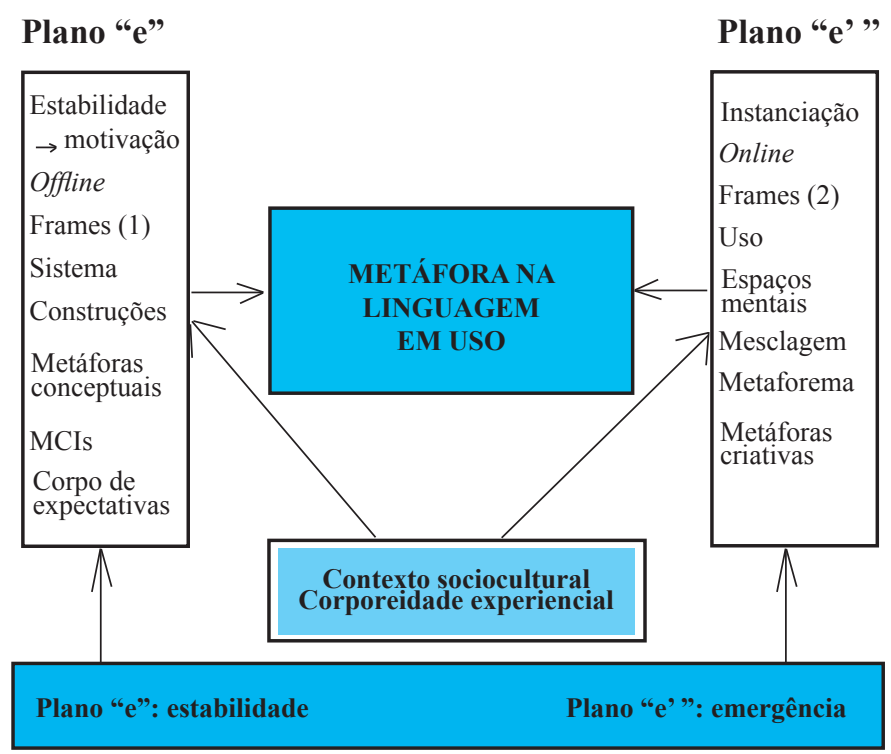

Figura 1: Entrelace dos planos " $\mathrm{e}$ " $\mathrm{e}$ " $\mathrm{e}$ " "

A linguagem metafórica mais convencionalizada poderia ser mais bem compreendida a partir do plano "e ", enquanto a mais inédita ou criativa, presente em vários nichos metafóricos, na poesia, no humor (Ex: "Mentes são que nem paraquedas: só funcionam quando estão abertas; "Mulher é que nem estrada: quanto mais curva, mais perigosa", e uma série de outras piadas com a construção "é que nem.. ."11), a partir do plano "e"". Entretanto, como foi observado nas discussões propostas anteriormente, falamos, sobretudo, em termos de um foco maior em um ou em outro plano. O que se observa, de fato, é a impossibilidade de se compreender o fenômeno da metáfora em uso a partir apenas de um deles.

11. Disponíveis no site (de humor duvidoso) : http://br.answers.yahoo.com/question/index?qid= 20070514132002AAKNX9h. Acesso em 10/04/2012. 
Por limitações metodológicas, é frequentemente necessário fazer recortes interplanos ou intraplanos. Ou seja, podemos investigar fenômenos que dizem respeito mais ao primeiro plano, ou ao segundo; ou a algumas instâncias do primeiro plano "e", como frames off-line, construções gramaticais, metáfora conceptual, MCIs etc. Nesse caso, provavelmente estaríamos fora dos parâmetros que definem a "experiência linguística" a que Coulson (2001) se refere. No entanto, ao mergulharmos na indeterminação do plano episódico, online, ou seja, ao empreendermos uma investigação da metáfora em uso, torna-se, a meu ver, imprescindível estabelecermos um diálogo sistemático entre elementos dos dois planos. Afinal, a metáfora em uso pode gerar a criação de novas telas da experiência, mas sempre a partir de pinceladas e retoques sobre telas de sentidos já existentes, mesmo que esses não alcancem, explicitamente, a superfície de nossa consciência.

\section{REFERÊNCIAS BIBLIOGRÁFICAS}

BLACK, M. Metaphor (1962). In: BLACK, M. (Org.) Models and Metaphor. New York: Cornell University Press.

BRONZATO, L, H. (2012). O segredo do sucesso que a gramática e a metáfora não escondem. In: VEREZA, S, C. Sob a Ótica da Metáfora: tempo, conhecimento e guerra. Niterói: EDUFF, p. 179 - 196.

CAMERON, L. (1999). Identifying and describing metaphor in spoken discourse data. In: CAMERON, L. e G. LOW (Orgs.) Researching and Applying Metaphor. Cambridge: Cambridge University Press.

Metaphor shifting in the dynamics of talk. (2008). In: ZANOTTO, M. S. et al. (Orgs.) Confronting Metaphor in Use: an applied linguistic approach. Amsterdam: J. Benjamins. . e DEIGNAN, A. (2006). The Emergence of Metaphor in Discourse. Applied Linguistics, n. 27(4), p. $671-690$. . e MASLEN, R. (2010). (Orgs.) Metaphor Analysis: research practice in applied linguistics, social sciences and the humanities. London: Equinox.

COULSON, S. (2001). Semantic Leaps: frame shifting and conceptual blending in meaning construction. Cambridge: Cambridge University Press.

DEIGNAN A. (2005). Metaphor and Corpus Linguistics. Amsterdam: John Benjamins.

FAUCONNIER, G. (1985). Mental Spaces: Aspects of meaning construction in natural language. Cambridge: The MIT Press.

FAUCONNIER, G. e TURNER, M. (1998). Conceptual Integration Networks. Cognitive Science, n. 22: 2, p. $133-187$.

FILLMORE, C. Frame Semantics. (2006). In: GEERAERTS, G. Cognitive Linguistics: basic readings. Berlim: Mouton de Gruyter, p. 373 - 400.

FORCEVILLE, C. J. e URIOS-APARISI, E. (2009). (Orgs.) Multimodal metaphor. Berlim: Mouton de Gruyter.

GEERAERTS, D. (2006). Cognitive Linguistics: basic readings. Berlim: Mouton de Gruyter. 
VEREZA - Entrelaçando frames: A construção...

GIBBS, R. (1984). Literal Meaning and psychological theory. Cognitive Science, n. 8, p. 275 304. .; BOGDONOVICH, J., SYKES, J., e BARR, D. (1997). Metaphor in idiom comprehension. Journal of Memory and Language, n. 37, p.14 - 154. .; e BOGDONOVICH, J. (1999). Mental imagery in interpreting poetic metaphor. Metaphor and Symbol, n.14, p. $37-44$.

GOLDBERG, A. (2006). Construction Grammar In: GEERAERTS, G. Cognitive Linguistics: basic readings. Berlim: Mouton de Gruyter, p. $401-438$.

HALlidAY, M. A. e MATTHIESSEN, C. M. (2004). An Introduction to Functional Grammar. Oxford: OUP.

HOUGAARD, A. E OAKLEY, T. (2008). Mental Spaces in Discourse and Interaction. Amsterdam: John Benjamins.

KÖVECSES, Z. (2005). Metaphor and Culture. Cambridge: Cambridge University Press.

LAKOFF, G. (1987). Women, Fire, and Dangerous Things. Chicago: University of Chicago Press. . (1993). The contemporary theory of metaphor. In: ORTONY, A. Metaphor and Thought (2 $2^{\mathrm{a}}$ ed.). Cambridge: Cambridge University Press, p. 202-251.

. (2004). Don't Think of an Elephant!: know your values and frame the debate. Vermont: Chelsea Green Publishing.

LAKOFF, G. e JOHNSON, M. (2002). Metaphors We Live by. Chicago: University of Chicago Press. Tradução em português pelo grupo GEIM: LAKOFF, G. e JOHNSON, M. Metáforas da Vida Cotidiana. Campinas, São Paulo, Mercado de Letras/EDUC. (original de 1980)

. (1999). Philosophy in the Flesh: the embodied mind and its challenge to western thought. Nova Iorque: Basic Books.

LAKOFF, G. e TURNER, M. (1989). More than Cool Reason: field guide to poetic metaphor. Chicago: University of Chicago Press.

RICHARDS, I. A. (1936). The Philosophy of Rhetoric. Oxford: Oxford University Press.

MIRANDA, N. S. (2009). Construções gramaticais e metáfora. Revista Gragoatá n. 26, p. 61 - 80.

SEMINO, E. (2008). Metaphor in Discourse. Cambridge: Cambridge University Press.

STEEN, G. (1994). Understanding Metaphor in Literature: an empirical approach. London: Longman.

VEREZA, S. C. (2006). Novos caminhos para o estudo da metáfora. In: ZYNGIER, S., VIANA, V. e SPALLANZANI, A. Linguagens e Tecnologias: estudos empíricos. Rio de Janeiro: Publit, p. 145 - 164.

. (2007). Metáfora e argumentação: uma abordagem cognitivo-discursiva. Linguagem em (Dis) curso, v. 7, n. 3, p 487 - 506.

. (2010). O Lócus da Metáfora: linguagem, pensamento e discurso. Cadernos de Letras da UFF, n. 41, p. 199 - 212.

. (2012). Sob a Ótica da Metáfora: tempo, conhecimento e guerra. Niterói: EDUFF.

ZANOTTO, M. S. et al. (2008). (Orgs.) Confronting Metaphor in Use: an applied linguistic approach. Amsterdam: J. Benjamins. 


\section{TEXTO III- A economia na toca do coelho}

Paul Krugman

Ler a transcrição do debate republicano dessa terça-feira sobre a economia, para qualquer pessoa que esteja acompanhando os acontecimentos na economia nesses últimos anos, é como cair na toca do coelho. De repente, você se encontra em um mundo de fantasia, onde nada parece ou acontece como no mundo real.

E já que a política econômica precisa lidar com o mundo em que vivemos, e não com o mundo de fantasia que existe na imaginação do Partido Republicano, a possibilidade de que um membro do partido seja o nosso próximo presidente é realmente assustadora.

No mundo real, os acontecimentos recentes são uma resposta devastadora por parte do conservadorismo do livre mercado, que tem dominado a política norte-americana nas últimas três décadas. Foram principalmente a longa cruzada contra o controle financeiro e a tentativa bem-sucedida de se afrouxarem as leis preventivas instituídas após a Grande Depressão, com o pretexto de serem desnecessárias, que acabaram mostrando que essas leis eram necessárias no final das contas.

Mas na toca do coelho, nada disso aconteceu. Não tivemos uma crise por causa de credores fujões do setor privado, como o Countrywide Financial.[...] Não, no universo do Partido Republicano, tivemos um crise porque o congressista Barney Frank forçou banqueiros indefesos a emprestarem dinheiro para os pobres que não o mereciam. [...]

É horrível quando uma pessoa se desprende da realidade. Mas é muito pior quando isso acontece com um partido político inteiro. [...]

\section{TEXTO IV- Uma dura caminhada pela frente} Bob Herbert

Walt Disney teria ficado orgulhoso com a apresentação de John McCain, nessa terça-feira, sobre como o mundo se parecerá ao fim do seu primeiro mandato como presidente.

Ouvir o seu discurso foi como atravessar os portões da Fantasyland, que, como Walt Disney sempre dizia, era o reino mais feliz de todos. A guerra do Iraque já terá sido ganha. $\mathrm{O}$ excelente trabalho do serviço de informações já terá levado à captura e morte de Osama bin Laden. Os impostos terão baixado e a economia norte-americana estará ótima. O senador McCain nem se deu ao trabalho de comentar como faríamos para alcançar uma situação tão maravilhosa, e chegou a se irritar quando um repórter insinuou que ele estava oferecendo um "passeio em um tapete mágico". 
VEREZA - Entrelaçando frames: A construção...

Elisabeth Bumiller, do The Times, foi muito feliz quando escreveu na edição de sexta-feira que "não havia fatos reais verificáveis na profecia de McCain". No mesmo dia em que o senador tornou públicas as suas belas ideias, o ex-governador de Virgínia do Oeste, Bob Wise, veio ao meu escritório falar sobre um assunto muito menos fantástico - o péssimo trabalho que o país tem feito para preparar as crianças do ensino médio para o mundo real.

[...] O trabalho do governo federal para melhorar a educação secundária deveria ser uma das prioridades da campanha presidencial, mas não é. Os Estados Unidos pararam de enfrentar abertamente problemas difíceis e complexos. Os políticos (e não somente John McCain, em todo caso) criam fantasias de um futuro maravilhoso e sem gastos.[...] 